\begin{tabular}{ll}
\hline \hline MINING AND METALLURGY INSTITUTE BOR & ISSN: 2334-8836 (Štampano izdanje) \\
UDK: 622 & ISSN: 2406-1395 (Online) \\
\hline \hline
\end{tabular}

UDK: $622.765 .061(045)=111$

doi:10.5937/mmeb1704103S

Dragiša Stanujkić, Dragan Milanovic ${ }^{* *}$, Srdjana Magdalinovic ${ }^{* *}$, Ivana Jovanovic ${ }^{* *}$

\title{
AN APPROACH TO THE EVALUATION OF FROTH FLOTATION REAGENTS BASED ON THE USE OF THE SWARA AND WS-PLP METHODS ${ }^{* * *}$
}

\begin{abstract}
The selection of the most suitable flotation reagents is very important in the froth flotation process because the recovery of valuable minerals largely depends on the reagent regime. On the other hand, the particular characteristics of the ore excavated from different mine sites have their own specificity that should be taken into account in choosing the most appropriate reagents. Therefore, a proposal for forming a framework for selecting the most suitable flotation reagents is discussed in this paper. The usability and efficiency of the proposed approach are considered on the conducted empirical example.

Keywords: reagents; froth flotation; MCDM; SWARA; WS-PLP
\end{abstract}

\section{INTRODUCTION}

Froth flotation is an industrial process widely used in the mineral processing for selective separation the finely liberated hydrophobic minerals.

The froth flotation separation process is based on attaching the very fine particles of valuable minerals to the surface of air bubbles. The efficiency of separation and utilization the valuable minerals largely depends on the hydrophobic character of mineral surfaces. Therefore, the flotation reagents have a substantial impact on utilization the valuable minerals, as well as the efficiency of flotation process.

There are a number of characteristics of the floated ore particles that could signifii cantly affect the separation of useful minerals. Therefore, the selection of appropriate reagents is not easy to do.

There are many, mutually conflicting, criteria that could have an impact on the selection of the most adequate flotation reagent, which is indicative of the fact that selection of the most adequate floatation reagent could be considered as a multiple criteria decision - making (MCDM) problem.

Therefore, this paper is organized as follows: In Section 2, the criteria relevant for selection the most appropriate flotation reagents are considered. After that, in Sections 3 and 4, the two characteristic MCDM methods intended for determining the weights of

\footnotetext{
* Faculty of Management in Zajecar, John Naisbitt University Belgrade, Park Suma Kraljevica bb, 19000 Zajecar, Serbia

** Mining and Metallurgy Institute Bor, Zeleni bulevar 35, 19210 Bor, Serbia

*** This paper is a partial result of the Project TR33023 financed by the Ministry of Education, Science and Technological Development of theRepublic of Serbia. The constructive comments of the referees are gratefully acknowledged
} 


\section{THE SWARA METHOD}

evaluation criteria and selecting the most appropriate alternative, respectively, are presented. Based on the previous considerations, a multiple criteria group decisionmaking approach is proposed in Section 5, whereas the usability and efficiency of the same are checked in Section 6. Finally, the Conclusions are given at the end of the manuscript.

\section{CRITERIA RELEVANT FOR SELECTION THE MOST RELEVANT FROTH FLOTATION REAGENTS}

There are a number of technological parameters depending on the flotation pulp conditions that indicate the successfulness of the flotation process (Magdalinovic, 2017; Langa et al., 2014; Lotter and Bradshaw, 2010; Bulatovic, 2007). In the cases of copper sulfide ore flotation, the following parameters could be stated as some of the most significant:

- recovery of $\mathrm{Cu}$ in concentrate,

- concentrate grade,

- tailings grade, and

- economic efficiency.

From the MCDM perspective, these criteria could not be easily characterized as the beneficial (revenue) and non-beneficial (cost) criteria. The main reason for this is the fact that the above-mentioned evaluation criteria are not mutually independent, which can especially be observed in a relationship between recovery and economic efficiency, i.e. changes in the recovery of valuable minerals, and throughput of flotation cells can significantly affect changes in the economic effects of flotation through a very complex relationship.

However, this problem can successfully be overcome using the WS-PLP method, which will be explained in the remaining part of this manuscript.
The SWARA method was proposed by Kersuliene et al. (2010). The SWARA method could be used to determine the weights of criteria and also to solve the complex multiple criteria decision-making problems. In addition to this, compared to the well-known AHP method, the SWARA method requires a significantly lower number of pairwise comparisons.

Based on Kersuliene et al. (2010) and Stanujkic et al. (2015), the computational procedure of the ordinary SWARA method can be precisely presented applying the following steps:

Step 1: Determination of a set of relevant evaluation criteria and sort them in descending order, based on their expected significances.

Step 2: Starting from the second criterion, determination the relative importance $s_{j}$ of the criterion $j$ in relation to the previous $(j-1)$ criterion, and do so for each particular criterion.

Step 3: Determination the coefficient $k_{j}$ as follows:

$$
k_{j}=\left\{\begin{array}{cc}
1 & j=1 \\
s_{j}+1 & j>1
\end{array} .\right.
$$

Step 4: Determination the recalculated weight $q_{j}$ as follows:

$$
q_{j}=\left\{\begin{array}{cc}
1 & j=1 \\
\frac{q_{j-1}}{k_{j}} & j>1
\end{array}\right.
$$

Step 5: Determination the relative weights of evaluation criteria as follows:

$$
w_{j}=\frac{q_{j}}{\sum_{k=1}^{n} q_{k}},
$$

where $w_{j}$ denotes the relative weight of the criterion $j$. 


\section{THE WS-PLP METHOD}

The WS-PLP method was proposed by Stanujkic and Zavadskas (2015) as an extension of the well-known Weighted-Sum Method. Based on Vujic et al. (2016), the computational procedure of the WS PLP method for an MCDM problem containing $m$ alternatives and $n$ criteria could be precisely expressed as follows:

Step 1: Evaluatation the alternatives in relation to the selected set of criteria.

Step 2: Defining the preferred performance ratings for each criterion. At this step, the decision - maker sets the preferred performance ratings for the evaluation criteria, thus forming the virtual alternative $A_{0}=\left\{x_{01}, x_{02}, \ldots, x_{0 n}\right\}$. If the decision maker does not have preferences for any criterion, it should be determined as follows:

$$
x_{0 j}=\left\{\begin{array}{l}
\max _{i} x_{i j} \mid j \in \Omega_{\max } \\
\min _{i} x_{i j} \mid j \in \Omega_{\min }
\end{array},\right.
$$

where $x_{0 j}$ denotes the preferred performance rating of the criterion $j$.

Step 3: Construction a normalized decision matrix. The normalized performance ratings should be calculated as follows:

$$
r_{i j}=\frac{x_{i j}-x_{0 j}}{x_{j}^{+}-x_{j}^{-}},
$$

where:

$$
\begin{aligned}
& x_{j}^{+}=\left\{\begin{array}{l}
\max _{i} x_{i j} \mid j \in \Omega_{\max } \\
\min _{i} x_{i j} \mid j \in \Omega_{\min }
\end{array},\right. \text { and } \\
& x_{j}^{-}=\left\{\begin{array}{l}
\min _{i} x_{i j} \mid j \in \Omega_{\max } \\
\max _{i} x_{i j} \mid j \in \Omega_{\min }
\end{array}\right.
\end{aligned}
$$

Step 4: Calculation the overall performance rating for each alternative, as follows:

$$
S_{i}=\sum_{j=1}^{n} w_{j} r_{i j}
$$

where $S_{i}$ denotes the overall performance rating of the alternative $i$.

Step 5: Calculation the compensation coefficient for the all alternatives with $S_{i}>0$, as follows:

$$
c_{i}=\lambda d_{i}^{\max }+(1-\lambda) \bar{S}_{i}^{*},
$$

with:

$$
\begin{aligned}
& d_{i}^{+\max }=\max _{i} r_{i j} w_{j} ; r_{i j}>0, \\
& \bar{S}_{i}^{+}=\frac{S_{i}^{+}}{n_{i}^{+}}, \text {and } \\
& \bar{S}_{i}^{*}=\frac{S_{i}^{+}}{n_{i}^{*}},
\end{aligned}
$$

where: $d_{i}^{\max }$ denotes the maximum weighted normalized distance of the alternative $i$ to the preferred performance ratings of the all criteria, so that $r_{i j}>0 ; \bar{S}_{i}^{*}$ denotes the average performance ratings achieved on the basis of the criteria, so that $r_{i j} \geq 0 ; n_{i}^{+}$denotes the number of criteria of the alternative $i$, so that $r_{i j} \geq 0 ; \lambda$ is coefficient, $\lambda=[0.1]$ and is usually set at 0.5 .

Step 6: Calculation the adjusted performance rating for the all alternatives $S^{\prime}$ with $S_{i}>0$, as follows:

$$
S_{i}^{\prime}=S_{i}-\gamma c_{i},
$$

where the decision-maker can reduce, or even eliminate, the impact of compensation coefficient varying the values of the coefficient $\gamma$.

Step 7: Ranking the alternatives and select the most efficient one. The considered alternatives are ranked by ascending $S_{i}^{\prime}$.

The usage of the compensation coefficient is not mandatory in the WS PLP method and can be omitted setting the value of coefficient $\gamma$ to zero. 


\section{A FRAMEWORK BASED ON THE USE OF THE SWARA AND THE WS-PLP METHODS}

The framework based on the SWARA and the WS-PLP methods can accurately be expressed through the following phases and the corresponding steps:

Phase I: Formation a team of experts who will carry out the evaluation, determine the set of available alternatives and form the set of the evaluation criteria.

Phase II: Determining the relevance and weights of evaluation criteria. In the proposed approach, the SWARA method is proposed for determining the weights of evaluation criteria.

Phase III: Evaluation the alternatives. The evaluation of alternatives is based on the use of the WS-PLP approach. The performances of alternatives in relation to the chosen evaluation criteria should be between 1 and 5, where any real number, located at the specified interval, could be used in order to make an evaluation more precisely.

Phase IV: Selection the most appropriate alternative. As a result of conducting the previous phase, the $K$ ranking orders of alternatives are obtained.

Based on the theory of ordinal dominance, the alternative appearing in the first position for the largest number of times is potentially the most appropriate one. However, in some cases, when the dominant alternative is not so easy to determine, the evaluation process should be sent back and the experts should reconsider its rating.

\section{AN EMPIRICAL ILLUSTRATION}

In this section, an example of selection the most adequate froth flotation reagents is considered so as to briefly demonstrate the efficiency and usability of the above- considered approach. The selection of the most adequate froth flotation reagents is considered on the ore excavated from the Veliki Krivelj Open Pit.

A team of experts was formed with the aim of proposing the most appropriate reagent from the following:

- $A_{1}$ - Potassium ethyl xanthate (PEX),

- $\mathrm{A}_{2}$ - TC 1000 ,

- $\mathrm{A}_{3}-$ Aero MX 5126, and

- $\mathrm{A}_{4}$ - S 10887.

For the purpose of making an evaluation of the above-mentioned alternatives, the team of experts has chosen the following criteria:

- $C_{1}$ - recovery of $\mathrm{Cu}$ in rougher concentrate, $\%$

- $C_{2}$ - content of $\mathrm{Cu}$ in rougher concentrate, \%

- $C_{3}$ - economic efficiency

- $C_{4}$ - specific surface area of rougher concentrate, $\mathrm{cm}^{2} / \mathrm{g}$

It should be noted that the criteria were considered under the following conditions: (1) grinding fineness $60 \%-75 \mu \mathrm{m}$ and (2) pulp $\mathrm{pH} 10$.

After that, the team of three experts has determined the weights of evaluation criteria applying the proposed approach, i.e. using Eqs (1)-(3). The values of relative importance $s_{j}$ for the selected criteria are shown in Table 1.

In this evaluation, the values of $s_{j}$ were determined on the basis of consensus of three experts.

In the next phase, the experts made an evaluation of the preselected flotation reagents in relation to the set of evaluation criteria. The obtained ratings, as well as the weights and preferred ratings obtained from three experts are given in Tables 2, 3 and 4. 
Table 1 The relative importance and weights of criteria

\begin{tabular}{ccccc}
\hline Criteria & $\boldsymbol{s}_{\mathbf{j}}$ & $\boldsymbol{k}_{\mathbf{j}}$ & $\boldsymbol{q}_{\mathbf{j}}$ & $\boldsymbol{w}_{\mathbf{j}}$ \\
\hline$C_{1}$ & & 1 & 1 & 0.49 \\
\hline$C_{2}$ & 0.90 & 1.90 & 0.53 & 0.26 \\
\hline$C_{3}$ & 0.70 & 1.70 & 0.31 & 0.15 \\
\hline$C_{4}$ & 0.50 & 1.50 & 0.21 & 0.10 \\
\hline & & & 2.04 & 1.00 \\
\cline { 3 - 5 } & & &
\end{tabular}

Table 2 The ratings, weighting and preferred ratings obtained from the first of three experts

\begin{tabular}{|c|c|c|c|c|}
\hline Criteria & $C_{1}$ & $C_{2}$ & $C_{3}$ & $C_{4}$ \\
\hline$w_{j}$ & 0.49 & 0.26 & 0.15 & 0.10 \\
\hline $\mathrm{A}^{*}$ & 4.70 & 4.00 & 4.50 & 5.00 \\
\hline$A_{1}$ & 3.10 & 4.00 & 3.00 & 2.00 \\
\hline$A_{2}$ & 3.90 & 3.00 & 3.20 & 5.00 \\
\hline$A_{3}$ & 4.70 & 2.50 & 4.50 & 3.00 \\
\hline$A_{4}$ & 4.20 & 3.50 & 3.30 & 4.00 \\
\hline
\end{tabular}

Table 3 The ratings, weighting and preferred ratings obtained from the second of three experts

\begin{tabular}{|c|c|c|c|c|}
\hline Criteria & $C_{1}$ & $C_{2}$ & $C_{3}$ & $C_{4}$ \\
\hline$w_{j}$ & 0.49 & 0.26 & 0.15 & 0.10 \\
\hline$A^{*}$ & 5.00 & 3.50 & 4.50 & 4.80 \\
\hline$A_{1}$ & 2.90 & 3.50 & 2.50 & 2.60 \\
\hline$A_{2}$ & 3.70 & 2.50 & 3.50 & 4.80 \\
\hline$A_{3}$ & 5.00 & 2.00 & 4.50 & 3.40 \\
\hline$A_{4}$ & 4.30 & 3.30 & 4.00 & 4.30 \\
\hline
\end{tabular}

Table 4 The ratings, weighting and preferred ratings obtained from the third of three experts

\begin{tabular}{|c|c|c|c|c|}
\hline Criteria & $C_{1}$ & $C_{2}$ & $C_{3}$ & $C_{4}$ \\
\hline$w_{j}$ & 0.49 & 0.26 & 0.15 & 0.10 \\
\hline$A^{*}$ & 4.80 & 3.70 & 4.50 & 4.80 \\
\hline$A_{1}$ & 3.00 & 3.70 & 2.70 & 2.50 \\
\hline$A_{2}$ & 3.90 & 2.70 & 3.10 & 4.80 \\
\hline$A_{3}$ & 4.80 & 2.50 & 4.50 & 3.10 \\
\hline$A_{4}$ & 4.20 & 3.50 & 3.30 & 4.20 \\
\hline
\end{tabular}


The normalized decision matrix and weighted normalized decision matrix formed on the basis of responses obtained from the first of three experts are accountted in Tables 5 and 6.

Table 5 The normalized decision matrix based on responses obtained from the first of three experts

\begin{tabular}{ccccc}
\hline Criteria & $\boldsymbol{C}_{\mathbf{1}}$ & $\boldsymbol{C}_{\mathbf{2}}$ & $\boldsymbol{C}_{\mathbf{3}}$ & $\boldsymbol{C}_{\mathbf{4}}$ \\
\hline$A_{1}$ & -0.20 & -1.05 & -1.27 & 0.00 \\
\hline$A_{2}$ & -0.40 & -0.53 & -0.91 & -0.50 \\
\hline$A_{3}$ & -0.76 & -1.53 & -0.36 & -1.00 \\
\hline$A_{4}$ & -1.20 & -0.53 & -1.36 & -0.50 \\
\hline$A_{5}$ & -0.20 & -1.05 & -1.27 & 0.00 \\
\hline
\end{tabular}

Table 6 The weighted normalized decision matrix based on responses obtained from the first of three experts

\begin{tabular}{ccccc}
\hline Criteria & $\boldsymbol{C}_{\boldsymbol{1}}$ & $\boldsymbol{C}_{\mathbf{2}}$ & $\boldsymbol{C}_{\mathbf{3}}$ & $\boldsymbol{C}_{\mathbf{4}}$ \\
\hline$A_{1}$ & -0.10 & -0.28 & -0.20 & 0.00 \\
\hline$A_{2}$ & -0.19 & -0.14 & -0.14 & -0.04 \\
\hline$A_{3}$ & -0.37 & -0.41 & -0.06 & -0.08 \\
\hline$A_{4}$ & -0.58 & -0.14 & -0.22 & -0.04 \\
\hline$A_{5}$ & -0.10 & -0.28 & -0.20 & 0.00 \\
\hline
\end{tabular}

In the same manner, the normalized decision matrix and weighted normalized decision matrix for the second and third experts were calculated. The performance ratings and ranking orders obtained on the basis of the responses obtained from the three experts are shown in Tables $7,8,9$ and 10 .

Table 7 The ratings and ranking orders obtained on the basis of responses of the first of three experts

\begin{tabular}{ccc}
\hline & $S_{\mathbf{i}}$ & Rank \\
\hline$A_{1}$ & -0.74 & 4 \\
\hline$A_{2}$ & -0.55 & 3 \\
\hline$A_{3}$ & -0.33 & 1 \\
\hline$A_{4}$ & -0.39 & 2 \\
\hline
\end{tabular}

Table 8 The ratings and ranking orders obtained on the basis of responses of the second of three experts

\begin{tabular}{ccc}
\hline & $S_{\mathbf{i}}$ & Rank \\
\hline$A_{1}$ & -0.74 & 4 \\
\hline$A_{2}$ & -0.55 & 3 \\
\hline$A_{3}$ & -0.32 & 2 \\
\hline$A_{4}$ & -0.26 & 1 \\
\hline
\end{tabular}


Table 9 The ratings and ranking orders obtained on the basis of responses of the third of three experts

\begin{tabular}{ccc}
\hline & $\boldsymbol{S}_{\mathbf{i}}$ & Rank \\
\hline$A_{1}$ & -0.74 & 4 \\
\hline$A_{2}$ & -0.58 & 3 \\
\hline$A_{3}$ & -0.33 & 1 \\
\hline$A_{4}$ & -0.34 & 2 \\
\hline
\end{tabular}

Table 10 The ranks obtained from three experts

\begin{tabular}{cccc}
\hline & Expert 1 & Expert 2 & Expert 3 \\
\hline$A_{1}$ & 4 & 4 & 4 \\
\hline$A_{2}$ & 3 & 3 & 3 \\
\hline$A_{3}$ & 1 & 2 & 1 \\
\hline$A_{4}$ & 2 & 1 & 2 \\
\hline
\end{tabular}

\section{REFERENCES}

As can be seen from Table 10, the alternative labeled as $A_{3}$ ranks the first twice and, based on the theory of dominance, it is evident that the alternative $A_{3}$ is the most appropriate alternative.

In other words, the Aero MX 5126 reagent was chosen as the most suitable for the ore excavated from the Veliki Krivelj Open Pit.

\section{CONCLUSIONS}

In this article, a framework for selecting the most adequate froth flotation reagent is proposed.

The usability and efficiency of the proposed framework are considered in the real case and its usability is confirmed by the obtained results.

The proposed criteria can be replaced by the other criteria, which is indicative of the fact that the proposed framework is flexible and convenient for solving similar problems. Finally, the proposed framework is based on the use of two efficient and easy-to-use MCDM methods that should enable the easier acceptance and use of the framework for selecting the most acceptable reagents.
[1] Bulatovic, S. M. (2007). Handbook of Flotation Reagents: Chemistry, Theory and Practice: Volume 1: Flotation of Sulfide Ores. Elsevier.

[2] Keršuliene, V., Zavadskas, E. K., \& Turskis, Z. (2010). Selection of Rational Dispute Resolution Method by Applying New Step- Wise Weight Assessment Ratio Analysis (SWARA). Journal of Business Economics and Management, 11(2), 243-258.

[3] Langa, N. T. N., Adeleke, A. A., Mendonidis, P., \& Thubakgale, C. K. (2014). Evaluation of Sodium Isobutyl Xanthate as a Collector in the Froth Flotation of a Carbonatic Copper Ore. International Journal of Industrial Chemistry, 5(3-4), 107-110.

[4] Lotter, N. O., \& Bradshaw, D. J. (2010). The Formulation and Use of Mixed Collectors in Sulphide Flotation. Minerals Engineering, 23(11), 945-951.

[5] Magdalinovic, S., Possibility to Increase the Bulk Density of Floated Particles Using Thiocarbonate - Master 
Thesis Theory. Technical Faculty in Bor, Bor, 2017 (in Serbian)

[6] Stanujkic, D., \& Zavadskas, E. K., A Modified Weighted Sum Method Based on the Decision -Maker's Preferred Levels of Performances. Studies in Informatics and Control, 2015, 24(4), 61-470.

[7] Stanujkic, D., Karabasevic, D., \& Zavadskas, E. K. A Framework for the
Selection of a Packaging Design Based on the SWARA Method. Inzinerine Ekonomika - Engineering Economics 2015, 26(2), 181-187.

[8] Vujic, D., Stanujkic, D. Urosevic, S. \& Karabasevic, D., An Approach to Leader Selection in the Mining Industry Based on the Use of Weighted Sum Preferred Levels of the Performances Method, Mining \& Metallurgy Engineering Bor, 2016, 4, 53-62. 